\title{
MEASURES AGAINST WATER POLLUTION IN INDUSTRIES WHICH PERFORM METAL FINISHING
}

\author{
S. H. JENKINS \\ Upper Tame Main Drainage Authority, Tame Valley House, \\ 156 Newhall Street, Birmingham 3, UK
}

\begin{abstract}
Effective legislation is the main driving force in controlling pollution and, indirectly in economizing in the use of water in industry. The control is exercised by municipal authorities over the discharge of waste water to public sewers or of river agencies that determine the quality of discharges to rivers. Important factors in the reduction of pollution in the metal finishing industries are factory lay-out; co-operation with local authorities so that the effect of any alterations in processing can be studied before treatment plant is installed; rationalization of factories; pretreatment enabling water to be re-used; and thorough survey of all water-using operations to make sure that any water used is essential for the success of the process.
\end{abstract}

The most important factor in the economy of water and the prevention of wastage of raw and finished materials in the metal finishing industries has been the need of manufacturers to comply with pollution control legislation. Although enlightened manufacturers now see the financial benefits that may spring from the introduction of measures that lead to economies in the use of water and consequently may lead them to adopt such measures voluntarily, this has not always been the case. In fact it does not date back more than 10 or 15 years. And in areas where water is cheap and plentiful and the manufacturer meets with no resistance in disposing of his process wastewaters into public sewers or rivers or estuaries, practices which are prohibited in an increasing number of urban areas still continue.

The main driving force in water economy is thus effective legislation that is enforceable and that is within the ability of industry to comply with if steps that are reasonable, practicable and not unduly costly are taken.

Although the subject of legislation and administrative control is outside the scope of this conference its universal importance to manufacturer and individual justifies a passing reference to the need for pollution control, insofar as it necessitates the installation of treatment plant or hydraulic control measures on industrial effluents. Agencies created for pollution control of water courses must obviously be responsible for determining the quality of all effluents that are discharged into the receiving water. Likewise, any municipalities that receive industrial waste water must be given the powers to 


\section{S. H. JENKINS}

control both the total volume and the rate of discharge as well as its composition. The agency responsible for pollution control must set the standards it requires for discharges to rivers with a view to preserving the water for specific purposes, and it may set its standards seemingly higher than would appear to be necessary because it anticipates that increasing quantities of water are likely to be abstracted for domestic and industrial purposes and then returned to the river as sewage effluent or trade effluent, so that the proportion of clean water available for dilution will thus be reduced. The use of the water for domestic purpose, for fisheries, for textile purposes and for recreational purposes all have to be taken into account in the formulation of standards of quality for discharges to rivers.

The position regarding discharges of industrial effluents to public sewers may be even more complicated, so much so that it may be difficult to lay down anything more than certain general principles that must be followed. For instance, the sewer must be physically capable of conveying the wastewater. A severe restriction may be necessary in the rate of discharge to accomplish this. An extreme case of this is where planning permission for the erection of a factory is refused because of inadequate sewer facilities, or because the sewer is already overloaded with wastewater.

A severe restriction in the discharge from a manufacturer's premises may be necessary if the rate of discharge and the composition of the wastewater are such as to result in undesirable overflows from a storm water overflow below the factory. In one case this has resulted in a limitation on the discharge of trade effluent more severe than would have been necessary to protect the sewage works where the wastewater was treated.

Manufacturers usually agree that it is reasonable that substances having a toxic effect on sewage treatment processes should be removed before the trade effluent is discharged to the public sewer or at least reduced in concentration to a level where such an effect does not occur. Again if the effluent from an otherwise efficient sewage treatment plant still contains such material that can be traced to industrial premises, that also gives the local authority the right to request its removal from the wastewater. Industrial effluents may affect the safety of men working in the sewer, the conveyance of the sewage in the sewer, the fabric of the sewer and the sewer capacity, the efficiency of sedimentation, biological oxidation, sludge treatment or the quantity of sludge obtained, the use to which the sludge may be put and the quality of the final effluent, and for one or all of these reasons some restriction may have to be placed on the discharge.

But what is the position when the river pollution control agency imposes unnecessarily stringent conditions on discharge to rivers, or municipal authorities demand standards of quality or restrictions in quantity that the manufacturer may feel are not justified? For example if one local authority that receives toxic wastes constituting a large proportion of its total flow imposes severe restrictions on the discharge of the toxic substances, should another authority that receives similar material in a much smaller proportion apply the same restrictive standards in order to make sure it always has complete control over such discharges?

It is greatly in the interests of manufacturers that they should be properly advised of the justness of any standards they are called upon to comply with 
and to support any legislation that gives them the right to question standards at a sufficiently early stage to allow them to take effective action to avoid unnecessary expenditure. Occasional references will be made in this paper to measures that have been of assistance to manufacturers in their dealings with river authorities and local authorities.

\section{IMPORTANCE OF FACTORY LAY-OUT}

In the metal finishing industries the greatest economies in the use of water, in the saving of material and in the cost of wastewater treatment plant can result from careful planning of units of production and the proper layout of plant requiring a water supply, the segregation of effluents according to the kind of treatment they require and consideration of the type of drainage system that should be installed. This may seem very obvious and prosaic but it cannot be over-emphasized that the maximum economy cannot be made if such matters are not taken into account at a sufficiently early stage.

The importance of the right kind of layout should be considered from the moment it becomes necessary to treat the factory effluent, assuming that one is dealing with an existing works which has not had to give consideration to this problem previously. The use of water in different component parts of the factory must be determined in relation to the output, using water meters or effluent recorders or making estimates of flow. The amount of chemical added at different processes should be obtained and this should be related to the content of chemical in the effluent. In some processes it is possible to obtain a reasonable estimate of the proportion of any added chemical that becomes a part of the manufactured product. In that case, calculation of the amount of the chemical that should be present in the effluent should be shown to agree with the actual composition of the effluent. At the same time data are required concerning the variation in the composition of the trade effluent so that one is in a position to gauge the effect of such variation on the capacity of any treatment plant that will have to be installed, or determine the necessity to balance the composition of the trade effluent. Information of this kind is particularly important if the factory covers a comparatively large area or if the units of production exist in separate buildings or if there has previously been no separation of rainwater falling on roofs and paved surfaces from the trade effluent.

To obtain such information may take a long time. In order to prove that this period of apparent inactivity during which no improvement in the nature of the discharge may occur is being put to good use, it is necessary to establish good relations with either the local authority or the water pollution control authority. The results of such a study may lead to the conclusion, particularly in some congested industrial or urban areas, that little can be done to minimize pollution except by measures that are impracticably expensive. In that event the industrialist has no other alternative than to install a treatment plant to deal with the effluent. That still leaves him with the opportunity to economize in the use of water or materials, if the survey has revealed that these show the use of excessive quantities, or even re-use some of the treated effluent. However, metal finishers go to such trouble and 


\section{S. H. JENKINS}

expense in cleaning metal surfaces before putting the finished surface on the metal, using clean water in considerable quantity so as to make sure the process is satisfactory that they are reluctant to re-use effluent unless this can be proved to be as satisfactory as the public water supply.

If the survey shows that by one method or another considerable improvements may be made it may be possible to persuade the municipality or pollution control authority to allow the manufacturer time in which to effect such improvements. To illustrate the variety of the circumstances that may arise one may quote the following cases:

A factory trade effluent containing chromium, nickel, copper, zinc, cyanide and acid had to be neutralized quickly on account of corrosion of a municipal pumping plant. The factory did not lend itself to redrainage. Considerable quantities of lime, amounting at times to tons per week were required at first. The effluents from the factory were then collected into a large tank, which served to balance these effluents in $\mathrm{pH}$ value before lime was added and the contents pumped out periodically to the sewer. The effect of the balancing was to reduce the consumption of lime by about 90 per cent.

On a large factory site trade effluent was drained to different public sewers. In order to satisfy the conditions of the local authority regarding toxic metals, cyanide and $\mathrm{pH}$, it would have been necessary to install treatment plant at three of the points of discharge. By co-operation with the local authority the factory relaid drains so that all the trade effluent drained to a central point. This made it possible to install a single trade effluent treatment plant at a cost, it has been claimed, of about $£ 100,000(\$ 240,000)$ less than the scheme that was originally thought to be necessary.

On another large site effluents containing acids and heavy metals were discharged into a river from a large number of outlets. Pressure from the river control agency compelled the manufacturer to seek permission to discharge the effluents into the public sewer. The local authority could only accept the effluents if they were neutralized, improved in quality and considerably reduced in volume, and then only on payment at a rate pro rata to the volume and the metals and suspended solids content of the effluent. It took a considerable period to establish where the main sources of pollution originated and to reduce the volume of waste water by separating all rain and surface water from trade effluent. Because of the inability of the municipality to accept the waste it became necessary to collect all the wastes into one pipe and then treat them in a neutralizing plant and provide settlement. The waste substances that entered the drains came from different parts of a large site. Consequently control had to be exercised within the factory in order to prevent flushes of waste material in concentrations beyond the capacity of the treatment plant. Although much improved the effluent still failed to satisfy the conditions of the river control authority. If the effluent had been discharged to the public sewer, assuming this had sufficient capacity to receive the trade effluent, the cost to the manufacturer would have been about $£ 10,000(\$ 24,000)$ to $£ 20,000(\$ 48,000)$ per annum. By installing sand filters following the settlement tanks the manufacturer has improved the effluent to the point where the effluent can be discharged, without cost, to the river. Additional treatment would probably result in water fit for re-use in manufacture or in steam raising. 
Another example of the importance of co-operation between manufacturers engaged in metal processing and local authorities concerns a site containing buildings undergoing reconstruction during a period of capital expenditure phased over several years. A large volume of effluent containing waste cutting oils, acids and plating compounds was produced in various buildings and it entered drains that were not easy to trace, causing a drainage problem that was difficult to solve on account of the lack of precise information about the consumption of water and the origin of the sources of pollution. The local authority allowed improvements in drainage and complete re-drainage to be made with each phase of factory re-development. Much use was made of plastic drains attached to walls above ground level so that wastes could be pumped from small sumps without having to lay drains in floors that had been laid to take heavy machinery. By the time site re-development had taken place all the effluents had been segregated into (1) fairly clean water that required no treatment before it was discharged to the public sewer, (2) acid waste that required neutralization and chromic acid that could be reduced and precipitated after neutralization and the resulting effluents, after settlement, discharged to the public sewer and (3) oil suds waste that were amenable to treatment by de-emulsification with aluminium salts. It became possible to re-use water required for scrubbing the air entering paint spray booths. During the process of reconstruction economies in water usage were introduced that resulted in halving the water consumption per unit of manufacture. This occurred during a period when finer clearances in one of the products of manufacture necessitated greater attention being given to the removal of oil suds by water.

These few examples show the supreme importance of establishing good relations between industry and public authorities responsible for pollution prevention so that the most efficient and the least costly method of treatment of effluent by industry is employed and so that the maximum economy in water use can be made.

\section{ECONOMIES IN WATER DUE TO RATIONALIZATION}

Rationalization is a process that can take place in an industry in order to obtain improved management or manufacture resulting from the enlargement or redistribution of operations. Similar objectives can be achieved by a group of factories under the same management. In the metal finishing industry there has been a tendency for finishing processes to be carried out by specialist firms. These generally are small efficient units. Usually in large factories metal finishing is subsidiary to such process as the assembly of finished parts. In the regrouping of factories within one organization, it is possible to achieve considerable economy of water by concentrating all the water-consuming and effluent producing operation, within one factory. Thus, on the amalgamation of three factories making fasteners the plating operations were concentrated in only one factory. The total water consumption of 160,000 gallons $\left(727 \mathrm{~m}^{3}\right)$ per day at the three factories fell to 100,000 gallons $\left(454 \mathrm{~m}^{3}\right)$ per day. At another factory making motor cars the water cooling systems within the one factory were rationalized. This 


\section{S. H. JENKINS}

resulted in a fall of 135,000 gallons $\left(613 \mathrm{~m}^{3}\right)$ per day in the volume of uncontaminated effluent per day. Generally, rationalization due to the merging of companies results in the concentration of such operations as plating in a single efficient plant within the group.

\section{METAL FINISHING PROCESSES}

A wide variety of industries make use of metal finishing processes. Sometimes the finishing of metals is carried out as one operation in a sequence of operations performed on one site in order to complete the manufacture of a product. Sometimes different parts of the product arrive at the assembly plant in a finished or partly finished condition. On occasions finishing processes that are normally carried out on the premises where the whole operation of manufacture is usually performed are sent out to be undertaken by a sub-contractor in order to obtain an increase in output that would otherwise be limited by the finishing processes.

Some of the principal industries that use metal finishing processes are the motor car industry; the aircraft industry; the kitchen and domestic ware industry; the heavy electrical industry; for the manufacture of electrical components; non-ferrous and ferrous parts for the building industry; ornaments and fancy goods such as ladies' handbags; and industries concerned with the treatment of steels such as stainless steel, tubes or steels meant to withstand very high temperatures.

It is unusual to find identical processes carried out on different premises. Hence, comparisons between the water consumption or the composition of the effluent from different factories may not give meaningful information. This is particularly true of well established industrial areas where in the course of time factories tend to specialize in operations they can carry out competitively.

The term metal finishing includes: Pretreatment, using solvents for degreasing and cleaning, chemical cleaning, pickling with acids, phosphating by dipping steel or zinc base alloys in a solution of acid phosphates, chromating, sodium hydride descaling, abrasive cleaning, shot blasting, ultrasonic cleaning, barrelling and polishing; Finish polishing using mechanical, barrelling, electropolishing or chemical processes; Electroplating using vat, barrel, automatic or reverse current processes to plate copper, nickel chromium, cadmium, tin, speculum (a tin-copper alloy), silver, palladium and other precious metals; Anodising in sulphuric or chromic acid; Metal coating by galvanizing, sherardizing (heat treatment of cleaned articles in the presence of zinc dust and aluminium or sand), Peen plating (non-electrolytic method of applying metal coatings to hardware articles), calorizing (heat treatment in the presence of ammonium chloride and powdered aluminium), chromating, zinc or aluminium spraying or hot dip aluminizing; Paint coating by brush, spray or electrostatic or airless processes, dipping, curtain coating, flow coating, rumbling, hot spraying or electropainting; Chemical colouring by blackening, blueing or chromating; Plastic coatings, applied by spray, dipping, fluidized bed, powder spraying; Pre-finished metals as painted, anodized, aluminized, galvanized or plastic-coated strip or sheet metal that has been coated. In the industries in which these processes are used, other 
operations that result in the production of effluents may be carried out. For instance, hydrofluoric acid, synthetic detergents, silicates and chromates may be present in the effluents from the manufacture of television tubes; hydrofluoric acid in effluents from the preparation of stainless steel components; and fluoborates in effluents from the electro-deposition of lead or iron.

Above all, in many engineering shops and assembly plants where metal finishing operations are carried out, effluents containing spent emulsified oils are obtained from oil suds. Special consideration must be given to the treatment of such effluents. In addition oil may be derived from the swarf or oil-contaminated turnings obtained from the machining of metals.

Not surprisingly, the wide variety of the processes used in metal finishing leads to effluents that may not be very complex in chemical composition from a single process but which are extremely complicated chemically when they are all present in a sewerage system. For instance, copper may be plated from a bath containing the cyanides of copper, sodium, besides Rochelle salt and sodium carbonate; lead may be plated on iron from a bath containing lead oxide, fluosilicate and glue; one process of nickel plating uses nickel sulphate and chloride, with boric acid and organic additives; while in tin plating tin fluoborate, fluoboric acid and boric acid are used. This may give rise to problems when a municipal authority has to determine the quality of the effluent it will permit a manufacturer to discharge into a public sewer.

\section{GENERAL PRINCIPLES TO BE USED IN DETERMINING WASTE}

In the last few years industry has become increasingly aware of the importance of avoiding wastage of water, especially where it is costly to buy or limited in quantity. In certain areas the difficulty or expense of wastewater disposal has increased this awareness. Besides, it can easily be shown that where water charges and effluent disposal costs are high and much water is used, economies in the use of water may make a substantial contribution to the profits of a company.

In order to minimize costs for water and wastewater treatment in a proposed factory if these represent a substantial part of the cost of manufacture, detailed information should be obtained concerning the volume of water available for immediate and future needs, its quality and variability in composition and the facilities available for disposal of any effluent, i.e. the capacity of the public sewer into which it may be discharged or the composition of the effluent that will be acceptable either to the public authority or the river authority if a direct discharge is to be made to a river. The more detailed the information there is about the composition of the effluent the more likely it is for the municipal authority to formulate conditions. This will help the authority to decide whether difficulties may arise from undesirable effects being produced in a receiving stream as a result of the presence of some proprietory chemical, the composition of which may not have been disclosed to the river authority in the preliminary stages of discussions. The industrialist should make ample allowance for the fact that it may not be administratively possible for some public bodies to give quick decisions regarding the quality 


\section{S. H. JENKINS}

of the effluent they will accept. On the other hand a point of considerable importance is that every water using concern should make a senior member of its staff responsible for water supply, effluent disposal and, if this also applies, atmospheric pollution. It is important that the manufacturer should have a good idea about the quality of the water he requires, especially if the public supply requires softening or ion exchange treatment. The advantage of considering such matters in the design stage is that wastewater that has to be treated to satisfy the requirements of the pollution control authority may be found to require only an inexpensive additional treatment in order to render it usable for some other process, such as rinsing or cooling water. If an abundant water supply of good quality is essential but cannot be guaranteed from the public supply, the manufacturer may be able to meet all his requirements economically by the further treatment of his effluent.

A manufacturer should also obtain full information about the cost of any water he has to purchase, the cost of effluent treatment and especially the probable increase in these charges over a period of years. Many public authorities have declared capital works schemes in hand or in mind that make it inevitable that predictable increases in charges will take place. The manufacturer should ask himself whether it is not better that he should face the initial cost of installing plant to recover water from his wastewater and thereafter obtain water at the cost of chemicals and labour, once the capital charges have been paid off. In the metal finishing industry the water quality requirements are not so stringent that they cannot reasonably be met by an effluent treatment plant capable of producing neutral water with the total dissolved solids reduced to $250 \mathrm{mg} / \mathrm{l}$, the chloride to $50 \mathrm{mg} / 1$, the temporary hardness and the sulphate to $200 \mathrm{mg} / \mathrm{l}$, but with zero suspended solids.

Consideration should also be given to the collection of rain water falling on a factory roof in order to save purchasing part of the water. In factories when in any case it is necessary to have a water storage tank in order to ensure an adequate supply during periods of heavy demand, the storage tank can if necessary act as the rainwater collecting tank.

In the layout of a new factory it pays to have regard to essential matters, some of which were referred to earlier in this paper, i.e. segregation of drains if this is not too costly, drains above ground level so as to allow for greater flexibility in the arrangement of plant, arranging water-using processes in one area, providing space for treatment, effluent recovery and sludge disposal and installing water meters at important points. Attention should be given to the levels at which tanks are set so as to obtain the maximum fall through the plant, with possible savings by the use of pipes of small diameter. In one case, by setting the floor of one shop only 10 inches above the designed level it became possible to gravitate the flow through a treatment plant instead of having to pump it.

The legal obligations of the manufacturer arising from the disposal or the treatment of his effluent must be taken into account in the layout of his factory. The occasional accidental discharge of untreated, harmful effluent into a public sewer may generally be of little consequence but if it results in sewer blockage or damage or causes danger to personnel in sewers or pump wells at sewage treatment plant or passes through a sewage works and damages a river the consequences to a factory could be disastrous. If valuable 
fishing rights or public water supplies are certain to be damaged by any accidental discharge of a strong waste liquor it should be assumed that an accident will occur sooner or later and that it is cheaper to take the necessary steps to prevent its having a damaging effect. This can be done by having the vat or tank surrounded by another tank capable of holding any leak that may occur. Additionally all such tanks may be arranged so as to discharge into a dry well or holding tank of sufficient capacity to retain the strong liquor in case of accident. Where land is available it can be put to use by irrigating the treated effluent over the land before discharging to a river. This also is of value in minimizing the effect of any plant or other failure.

In existing factories the way to minimize water consumption and wastage of material is by a logical, systematic survey of all processes carried out as objectively as possible on the shop floor with the co-operation of shop floor personnel, covering all the possible conditions of manufacture. This will reveal whether the water usage is constant, regardless of the throughput of work, whether water is used at the normal rate during lunch or other breaks for meals, whether there is a difference between the factory water consumption during different shifts, how the composition of the effluent varies under the conditions just mentioned, how the water consumption varies in different parts of a factory where the water pressure may drop. These observations have to be carried out several times, particularly where the operations are not fully automatic. If possible all water used for sanitary, canteen and laundry purposes should be metered separately. Usually it is necessary to make a separate connection for this wastewater to the public sewer. No charge is usually made for such domestic waste.

After having checked that the water consumption figures are correct-a necessary though elementary precaution which may reveal that large quantities of water are disappearing through worn valves or burst pipes, or clean water is flowing from the factory when all operations have ceasedvarious methods of reducing water consumption and loss of material may be tried. Since blemishes may occur in some finished articles some time after the goods have been delivered to the customer, the management may show an understandable reluctance to depart from any satisfactory routine procedure.

Measures that have been found to be satisfactory and introduced into many metal finishing establishments in the United Kingdom by manufacturers or users of equipment are : restricted orifices in pipelines in order to supply a constant flow, on/off foot pedals for controlling the water supply to hand operated processes, intermittent rinsing of work, the use of water sprays or mist sprays, the use of static rinse tanks, countercurrent flow in rinse tanks, air agitation in rinse tanks in order to improve the efficiency of rinsing by increased turbulence, recycling of cooling water, the addition of chemicals to the rinse water so as to obtain a substantial reduction in the concentration of the material that has to be removed by washing with water, automatically controlling the discharge of liquid from the rinse tank and admitting clean water by measurement of the conductivity. In determining the amount of water necessary to obtain satisfactory rinsing by a particular method measurement of conductivity of the outflow may be made or the determination of one of the constituents being removed by washing may be carried out. 


\section{S. H. JENKINS}

Once the constituent has reached a sufficiently low concentration or a steady state by the use of a given rate of supply of rinse water any additional supply is wasted.

Economy in the use of water in rinsing and in rinsing plant is greatly increased compared with a single tank which may have an efficiency of only 5 per cent by the use of two or more tanks with counter current flow and with sufficient turbulence produced by air agitation to enable the product to be rinsed in a few seconds. If tanks are found to be too large it may be practicable and economical to divide them so as to give counter current flow. Harris ${ }^{1}$ found that with a single rinse tank 280 gallons (12721) per hour was required to produce a given rinse water quality but with two counter current flow tanks 17 gallons (77 1) per hour was needed and 6.5 gallons (301) per hour with three tanks. These findings agree within practical limits with the theoretical relationship that has been derived to show the connection between the rate of supply of rinse water and the number of counter current flow tanks required to produce a rinse water of given composition, i.e. $R=(p Q)^{\mathrm{n}} / \theta$

where $R=$ concentration of salts in process tank divided by the steady state concentration in rinse water

$p=$ time interval between rinsing operations

$Q=$ water flow in unit time

$\theta=$ dragout volume in unit time

$\mathrm{n}=$ number of tanks in series.

It is not necessarily disadvantageous if by reducing the volume of rinse water the effluent has a greater concentration of contaminants since treatment of the effluent is, if anything, thereby improved, and of course the size of the treatment and other costs are reduced.

The volume of rinse water discharged as trade effluent can also be reduced by other methods such as: encouraging evaporation from nickel baths by operating at the maximum temperature, blowing air over the surface, reducing the volume of liquid adhering to work entering the tank, removing work from the tank smoothly and allowing it to drain properly, by rinsing intermittently and using sprays for rinsing and by using demineralized water for rinsing so as to reduce the rate of salts build up; the discharge of waste rinse water may be eliminated by the partial demineralization of the rinse and the return of the demineralized water to the counter current rinse system. In automatically operated plant, the rate of water supply through electrically or mechanically operated valves should be measured and compared with the actual requirement. Furthermore where articles are rinsed by spray jets the jets should spray only when work is over the jet if production is not continuous and should cease to spray if the flow of work stops. In this connection, automatic flushing arrangements in toilets, spring loaded or other forms of tap in wash rooms should be set as to supply enough water for their purpose but without wasting it. In metal finishing, ion exchange resins are in use for the provision of good quality water, and to avoid loss of rinse water. ${ }^{2}$ Metals may be recovered from swills. If demineralized water is needed it may be obtained by recycling rinse water low in contaminant through an ion exchange plant. Organic brighteners present may have to be removed on an activated carbon column before 
ion exchange treatment. With cyanide plating the use of alkali cleaners and the highly alkaline nature of cyanide baths causes the rinse water to have a high sodium ion strength, which calls for a high level of regeneration of ion exchange resins. In this connection cationic resins may have to be regenerated with hydrochloric acid if the local authority places a severe restriction on the sulphate content of the final effluent admitted to the public sewer. Precipitation of cyanides on the resin may occur or strong absorption of nickel cyanide, resulting in resin poisoning.

In some factories, cooling water and uncontaminated water may be produced, not necessarily from metal finishing operations. Such water should be separated and recycled for re-use or used in some other operation.

Methods which have proved effective in reducing water consumption in the United Kingdom are (1) the use of fog and spray rinses which are recirculated and discharged at intervals. By this means and the use of small tanks in series the water consumption at one of the largest plating and aluminium anodizing plants has been reduced to 2800 gallons $\left(12.7 \mathrm{~m}^{3}\right)$ per hour $\left(12.7 \times 10^{3} \mathrm{l} / \mathrm{h}\right)$ (2) the sequential use of the same swill water for several different swill duties, (3) the use of condensed water vapour to effect rinsing. However, by taking simple economy measures the water requirements of a chromium plating plant consisting of cathodic and anodic cleaning, copper plating from a cyanide bath, followed by nickel and the final chromium plating, the water consumption was reduced from 1770 gallons $\left(8 \mathrm{~m}^{3}\right)$ per hour to 585 gallons $\left(2.7 \mathrm{~m}^{3}\right)$.

\section{CONTAMINANTS PRESENT IN METAL FINISHING WASTEWATER}

The experience we have gained in the examination of tens of thousands of effluent samples from metal finishing processes leads to the conclusion that only the broadest generalizations may be made concerning their composition. Even from a single shop there may be extremely wide differences in the level of contamination. The differences that have been found are so great that consultants or managements investigating water management at a factory are justified in starting with the assumption that wastage of water occurs somewhere in the operation and that there is scope for economy in the usage of chemicals. There is evidence that unsupervised maintenance work is responsible for some of the enormously high contents of valuable constituents in effluents, resulting from such practices as the uncontrolled discharge of vat contents.

Examples of the composition of metal finishing waste have been given elsewhere ${ }^{4}$ and it is sufficient to indicate that pickling processes will result in high soluble iron concentrations, even in swill water, with correspondingly high insoluble hydroxides after neutralization to at least $\mathrm{pH} 8$; brass and copper pickling liquors will contain a high content of copper, with some zinc; electroplating effluents will generally be acid, usually with up to 200 or $300 \mathrm{mg} / \mathrm{l}$ of suspended solids, copper nickel and zinc in varying amounts, perhaps up to 300 to $600 \mathrm{mg} / 1$, occasionally with chromium or cadmium or lead and frequently with cyanide present. The cyanide content will sometimes reach several hundreds of $\mathrm{mg} / \mathrm{l}$. Processes like blacking give rise to much 


\section{S. H. JENKINS}

solid matter in suspension and small concentrations of metals in solution. Water used for cooling purposes is apt to pick up considerable amounts of organic matter, sufficient to make it highly polluting. Organic matter is also a constituent of a number of metal finishing effluents, which could be objected to in the case of a direct discharge to a river. The sources of some of the organic matter are the organic additives used in some processes. The water from paint spray booths may have a high content of organic matter. Spent oil suds are not only a source of waste oil but also of soluble organic, bactericidal substances which can raise the organic content of an effluent to high level. Fluorine generally present as hydrofluoric acid though presumably also as fluoborates is derived from several sources such as the etching of glass and the preparatory cleaning of glass tubes. Fluoride has been found in effluents from the treatment of aluminium and its alloys. The most important process giving rise to the fluorides in effluents is the pickling of stainless steel which may give rise to waste liquors containing $13000 \mathrm{mg} F$ per litre. There is no problem in reducing this concentration to $8 \mathrm{mg} \mathrm{F} / \mathrm{l}$ by suitable treatment. However, the sewage from a population of over 100000 inhabitants in an area where such processes are carried out may exceed $3 \mathrm{mg} \mathrm{F} /$.

\section{MEASURES REQUIRED IN ORDER TO PREVENT POLLUTION}

Direct discharges of industrial effluents to rivers generally have to meet the same conditions as sewage effluents, i.e. they may have to be within a $\mathrm{pH}$ range of about 6 to 9 , contain not more than:

30 or $40 \mathrm{mg}$ suspended solid per litre

$0.1 \mathrm{mg} \mathrm{CN} / 1$.

$0.5-1 \mathrm{mg}$ of the common heavy metals per litre and

have a limiting content of organic matter.

Other restraints may be placed on the discharge, depending upon the circumstances; oil, for instance, may be limited to a few $\mathrm{mg}$ per litre.

These conditions can all be met if the manufacturer is prepared to pay the cost. The cheapest and most satisfactory arrangement is to dispose of the trade effluent to the public sewer. This usually places the manufacturer under the obligation to keep his discharge within limiting rates of flow and restrict the composition of the effluent. Frequently the manufacturer has no alternative but to install some form of pretreatment before the municipal authority will accept his discharge and in addition some form of payment may also be required.

From what has already been stated about the considerable variation in the composition of effluents from metal finishing processes it is clear that there is no standard form of treatment which could be said to be applicable to all. Each factory problem has to be studied separately. But there are a number of principles which apply to most situations. For instance, treatment to a standard suitable for discharge to a river or to a sewer should not be considered until steps have been taken to bring down the volume and strength of the effluent to the irreducible minimum including the possible benefits of layout and reorganization; the physical practicability of separating effluents into those that require treatment and those that do not should be 
considered, as well as the resultant overall economic benefits, including the possible recycling of water; consideration of the fact that a municipality may be prepared to accept a very bad effluent and charge for it at a rate much below the cost of pretreatment ; and the importance of siting a treatment plant where it will not restrict future development and where it will be able to deal with extra flows from such expansion should not be overlooked. The application of these principles may be illustrated by actual examples.

In the manufacture of motor car and light aircraft engines at Rolls-Royce Limited, Crewe, England, about 500000 gallons $\left(2273 \mathrm{~m}^{3}\right)$ of water are used daily. More than half of this is fit for discharge to a stream. Up to 250000 gallons $\left(1137 \mathrm{~m}^{3}\right)$ per day may be discharged to a public sewer subject to a number of conditions, including a limit for cyanide of $5 \mathrm{mgCN} / 1$, cadmium, chromium, copper, lead, nickel, tin and zinc of $10 \mathrm{mg} / \mathrm{lin}$ solution, $20 \mathrm{mg} / \mathrm{lin}$ total and $\mathrm{Cr}^{6+} 3 \mathrm{mg} / \mathrm{l}$. Part of the flow only requires neutralization before it is suitable for direct discharge without settlement to the sewer. The trade effluent arises from 16 points in a long established factory and from each it is transported to a central treatment plant about $\frac{1}{4}$ mile away by pumping into overhead pipelines which drain to the plant. Strong spent solutions are held in tanks where they arise and are pumped slowly at a controlled rate into the swill water. By reorganization, the flow of wastewater from the plating shop was reduced from 16000 gallons $\left(72.7 \mathrm{~m}^{3}\right)$ per hour to 3000 gallons $\left(13.6 \mathrm{~m}^{3}\right.$ ) per hour. The effluents were segregated into; 2070 gallons per hour of swills containing chromium, which was treated with $\mathrm{SO}_{2}$ at a controlled $\mathrm{pH}$ using redox control; 1740 gallons $\left(7.9 \mathrm{~m}^{3}\right)$ per hour of water containing cyanide, which was treated with chlorine at a controlled $\mathrm{pH}$ and redox potential: 3220 gallons $\left(14.6 \mathrm{~m}^{3}\right)$ per hour of swill water requiring neutralization with the treated chrome and cyanide swills, followed by discharge to the sewer after settlement in a 40000 gallon $\left(182 \mathrm{~m}^{3}\right)$ tank; and 4740 gallons $\left(21.5 \mathrm{~m}^{3}\right)$ per hour of water requiring neutralization before being discharged to the sewer. Sludge is dewatered on a rotary vacuum filter. The use of about 3 miles of P.V.C. plastic piping above ground was some $£ 25000$ ( $\$ 60000$ ) less in cost than underground pipelines ${ }^{3,5}$. This plant shows the economic benefits of segregation and of reducing wastewater by a careful study of the problem, and also demonstrates that segregation can be achieved in an established factory.

The second example concerns the treatment of chromium and zinc plating effluent from Joseph Lucas Ltd., Cannock, England ${ }^{6}$. Effluent could be produced at the rate of 20000 gallons $\left(91.3 \mathrm{~m}^{3}\right)$ per hour but because of local circumstances the treated discharge passing to the public sewer was limited to 14000 gallons $\left(63.6 \mathrm{~m}^{3}\right)$ per hour with a limiting heavy metal content of $10 \mathrm{mg} / \mathrm{l}$ and a $\mathrm{Cr}^{6+}$ limit of $2 \mathrm{mg} / 1$. Demineralized process water was required for processing at the rate of 8600 gallons $\left(39 \mathrm{~m}^{3}\right)$ per hour. The hourly wastewater flows in gallons, were: alkaline effluent $7700\left(35 \mathrm{~m}^{3}\right)$; acid effluent $5000\left(22.7 \mathrm{~m}^{3}\right)$; cyanide $4000\left(18.2 \mathrm{~m}^{3}\right)$. For the various liquors seven separate pump lines were provided, with separate tanks to hold strong liquors so that they could be delivered into the running flows at a controlled rate and then treated automatically by chromate reduction and cyanide chlorination. The seven lines were for cyanide swills, acid alkaline swills, chrome swills, strong cyanide dump liquors, strong acid dump liquors, 


\section{S. H. JENKINS}

strong caustic dump liquors and strong chromic acid. The cyanide and chrome liquors, after treatment join the main flow, receive neutralization and then settlement in an 88000 gallon $\left(400 \mathrm{~m}^{3}\right)$ tank. Sludge is dewatered on a rotary vacuum filter. This example illustrates a complete identity of interests - by a local authority under a High Court injunction not to lower the quality of the brook water receiving sewage works effluent and a manufacturer co-operating by taking unusual steps to comply with strict limitations on the volume and composition of his treated trade effluent.

The third example illustrates the point that has already been emphasized of treating metal finishing effluent in order to render it fit for reuse. The treatment of the effluent is integrated with the finishing processes instead of it being a separate, independent operation ${ }^{7}$. Treatment is carried out by delivering to the first rinse tank from a storage tank a dilute solution of chemical, which reacts with the substance that has been removed from the finished work. Instead of overflowing to waste the overflow from the rinse tank is delivered to the storage tank. This circulation from storage tank to rinse tank and back is continuous. The storage tank holds a large volume of the treatment solution and its design facilitates the settlement of the insoluble metal hydroxides which are precipitated by the chemical added to the rinse tank. Thus, for cyanide treatment, liquid from the storage tank is made alkaline by injection of alkali into the liquid as it passes through a chlorinator and then into the rinse tank. The overflow from the rinse tank flows back to the storage tank. Work from the first rinse tank passes into a second, clean water rinse tank in order to remove the de-toxicated alkaline drag out from the first rinse tank and this is led off to the sewer or river.

With chromium treatment, $\mathrm{SO}_{2}$ is injected into the storage tank liquid as it passes through a sulphonator on its way to the rinse tank. The chromate is reduced to trivalent chromium which remains in solution because the liquid is acid. The work passes into a second rinse tank into which an alkaline solution from a separate storage tank is fed in order to neutralize the acid and precipitate chromium hydroxide. The work is then rinsed in a final tank and the overflow discharged as waste. Where this method of treatment is applicable and land is available for dewatering the sludge in a lagoon, comparisons show that treatment costs are less than by separate purification of the effluent. It is rarely possible to recover the whole of the effluent obtained from any process but this example shows that partial recovery of effluent can be made to pay for itself and cost less than discarding all the treated effluent.

One may conclude, therefore, that economies in the use of water conserve resources, save manufacturers in costs and assist in the diminution of pollution. Pollution is diminished because metal finishing wastes on treatment give just as good results with strong wastes as with weaker liquors. Economy in the use of water, because it directs attention to wastage in general, usually results in the reduction of losses of chemicals, which reduces the capacity of any treatment plant required. The probability that water will become an increasingly valuable raw material and therefore a more costly one leads to no other conclusion than that it is in the interests of manufacturers to consider the reclaimation of used process water by the adoption of techniques that have become available in recent years. 


\section{WATER POLLUTION IN METAL FINISHING INDUSTRIES}

\section{REFERENCES}

${ }^{1}$ E. P. Harris, A survey of nickel and chromium recovery in the electroplating industry Dept. of Sci. \& Ind. Research, London 1960, p 11 and 26.

2 J. Pilot, The treatment of industrial effluent Eff. and Water Treatment J. 1970, April, pp 11-15.

${ }^{3}$ R. K. Chalmers, Water supply and waste-water disposal in the metal-working industry in Great Britain Aqua Conference, Basle, May 30, 1969.

4 S. H. Jenkins, Acceptance of waste water by Local Authorities Inst. of Metal Finishing, Symposium, London, March 15, 1967.

5 Rolls-Royce Limited, Motor Car Division, Pym's Lane, Crewe, Trade Effluent Treatment Plant 2nd July, 1969, (Brochure printed for the official opening of the treatment plant).

6 R. K. Chalmers, Trade effluent treatment at the Cannock Factory of Joseph Lucas Ltd. J. Inst. Sew. Purif. 1965, 357.

${ }^{7}$ R. Pinner, Private communication, also Rinse water recirculation in combination with the Integrated Waste Treatment Method. Inst. of Metal Finishing Symposium, London, March 15, 1967, and Cost of operation for an effluent treatment plant with rinse water recirculation Lecture, Soc. Chem. Ind. Effluent Treatment Group, April 24, 1969. 